\title{
Giant mucinous cystadenoma of ovary in an adolescent girl: a case report
}

\author{
Gaurav Singh ${ }^{1 *}$, Anupriya Narain², Shashi Dhawan ${ }^{3}$, Rajeev Kulshrestha ${ }^{1}$
}

\begin{abstract}
${ }^{1}$ Department of Pediatric Surgery, ${ }^{3}$ Department of Pathology, Sir Ganga Ram Hospital, New Delhi, India
${ }^{2}$ Department of Obstetrics and Gynecology, Lok Nayak Hospital and MAMC, New Delhi, India
\end{abstract}

Received: 31 October 2020

Accepted: 09 December 2020

\author{
*Correspondence: \\ Dr. Gaurav Singh, \\ E-mail: gauravpsurg86@gmail.com
}

Copyright: () the author(s), publisher and licensee Medip Academy. This is an open-access article distributed under the terms of the Creative Commons Attribution Non-Commercial License, which permits unrestricted non-commercial use, distribution, and reproduction in any medium, provided the original work is properly cited.

\begin{abstract}
Ovarian masses are rarer in children and adolescent than adults. Simple ovarian cysts are most common nonneoplastic masses in children. We report this case to emphasize that mass abdomen in adolescents can be missed being asymptomatic. A 16-year-old girl presented intermittent pain abdomen, nausea and decreased appetite for 3 months. Her menstrual cycles were normal and regular. Tumor markers were within normal limits. Exploratory laparotomy with decompression of cyst followed by cystectomy was done. The histopathology revealed the mass to be a mucinous cystadenoma. Post op course was smooth. The patients' age, size of the cyst and menopausal status of the patient are the important deciding factor in the plan of management. A conservative surgical procedure should be the primary aim in order to preserve patient's fertility.
\end{abstract}

Keywords: Adolescent, Abdomen, Laparotomy, Mucinous cystadenoma, Ovary

\section{INTRODUCTION}

Ovarian masses in children constitute a wide spectrum of pathology ranging from benign simple cysts to aggressive malignant tumours. In general, ovarian masses are rarer in children and adolescent than adults. Simple ovarian cysts are the most common non neoplastic masses in adolescent age group. ${ }^{1}$ Mature cystic teratoma is the most common benign neoplasm and amongst malignant neoplasms, germ cell tumours are the commonest. ${ }^{2,3} \mathrm{We}$ report a case of large ovarian mass in a 16-year-old girl; the histopathology of which confirmed the diagnosis of mucinous cystadenoma. Mucinous cystadenoma of ovary which although is a fairly common diagnosis in middle aged females, is a rarer entity in in children and adolescents.

\section{CASE REPORT}

A 16 -year-old girl presented to the pediatric casualty of Sir Ganga Ram hospital with complaints of intermittent pain abdomen, nausea and decreased appetite for 3 months. Her menstrual cycles were normal and regular. On examination, a mass corresponding to a 28 weeks size pregnant uterus was palpable per abdominally. It was a tense mass with regular margins and smooth surface, cystic to firm in consistency, non-tender and mobile from side to side. Tumour markers i.e., CA125, LDH, alpha feto protein and beta- hCG were advised for the patient and were within normal limits. Ultrasound was suggestive of a large homogenous cyst with multiple septa likely arising from the ovary. Contrast enhanced tomography was performed which confirmed the large multiseptated abdominopelvic mass of around $23 \times 12 \times 13$ $\mathrm{cm}$ arising from left ovary. Uterus and contralateral tube and ovary were normal (Figure 1). There was no radiological evidence of any peritoneal/organ implants or lymphadenopathy. A provisional diagnosis of a benign left ovarian mass was made.

The patient underwent exploratory laparotomy and cystectomy. Per operatively, there was a large cyst of 
around $25 \times 15 \mathrm{~cm}$ originating from left ovary with minimal peritoneal fluid (Figure 2). There were no peritoneal or omental implants. Right tube and ovary and other abdominal organs were grossly normal. No lymph nodes were palpable. Post-operative period was uneventful.

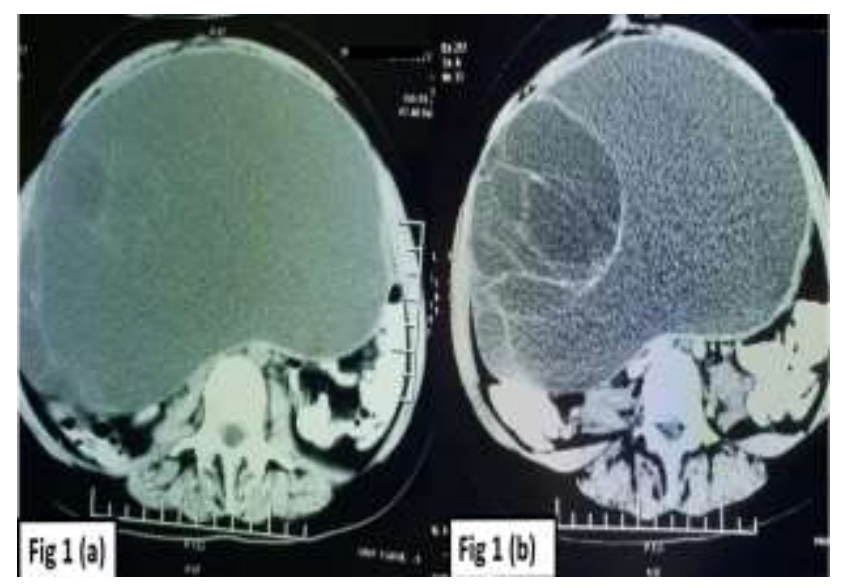

Figure 1: (a and b) large multiseptated abdominopelvic mass arising from left ovary.

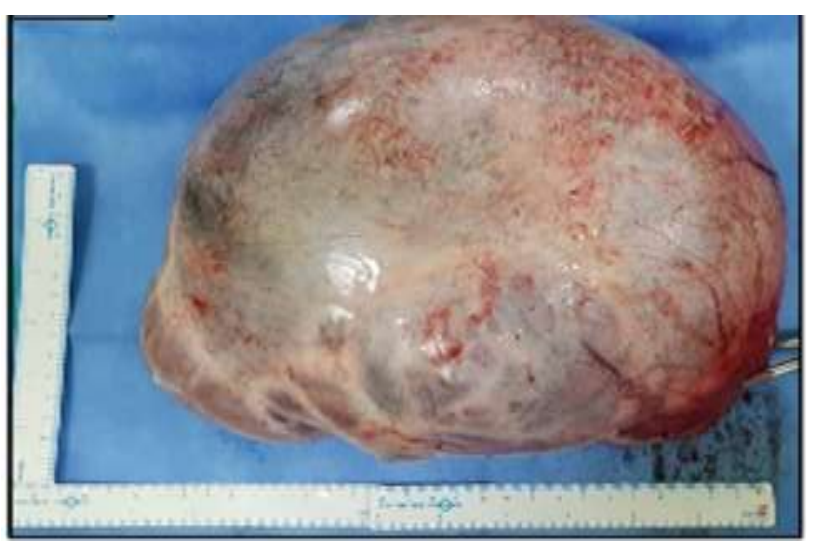

Figure 2: Large cyst of $\sim 25 \times 15 \mathrm{~cm}$.

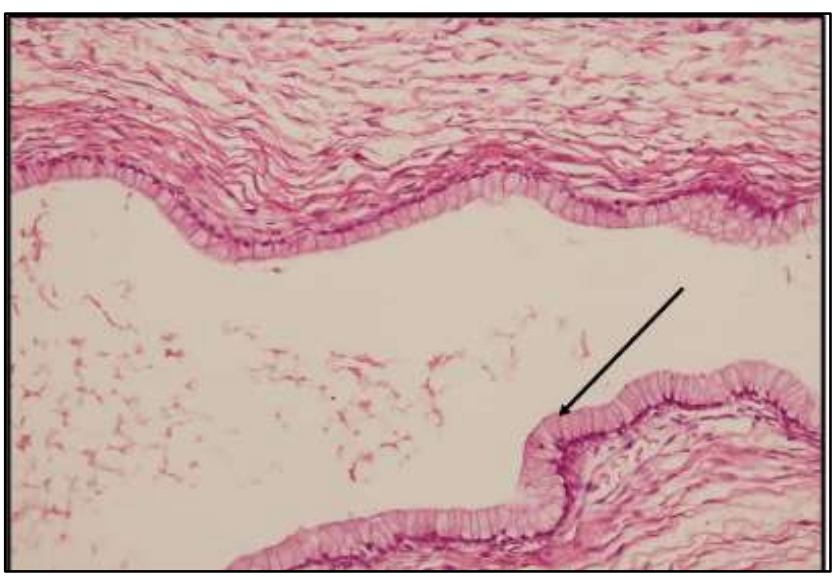

Figure 3: Single row of tall, columnar mucinous epithelium with apical mucin and basal nuclei (Arrow) (H.E. stain-maginification-40X).
The histopathology report showed a multiloculated cystic lesion lined by single row of tall, columnar mucinous epithelium with apical mucin and basal nuclei, suggestive of mucinous cystadenoma of ovary (Figure 3). The patient was followed up and was asymptomatic and menstruating normally.

\section{DISCUSSION}

Adolescent girls with ovarian mass may be asymptomatic and a mass may be detected only incidentally at a routine examination. However, others may present with symptoms such as lower abdominal fullness/pain, urinary frequency or retention, loss of appetite, constipation, nausea, vomiting or menstrual irregularities. Rarely, they may present with dyspnea, orthopnea, supine hypotension, hydronephrosis or with pleural effusion. ${ }^{4}$ The presentation as an acute abdomen may be related to the sudden complications like torsion, hemorrhage or rupture. Torsion is usually unilateral ( $80 \%$ cases) with predominance on right side. ${ }^{5}$

The differentials vary from a functional cyst of the ovary to the tumor/cysts arising from the surrounding organs. Commonly, the functional cysts are unilocular and anechoic with thin border. Other common differentials in children include omental cysts, mesenteric cyst, pancreatic pseudocyst, gastro-intestinal duplication cyst or lymphangiomas. Very large cysts may also raise the suspicion of a splenic cyst, multi-cystic dysplastic kidney or a large uterine tumor. ${ }^{6}$

On the basis of original cell types, the ovarian masses are divided into 3 groups; epithelial, stromal and germ cells. Epithelial tumors arise from Mullerian germinal epithelium and are the most common type in general. The most common benign ovarian neoplasm in the younger group is benign cystic teratoma. Serous or mucinous cystadenoma are rare in children. ${ }^{7}$

The ultrasound of abdomen and pelvis remains the most important modality for the diagnosis of ovarian masses. Depending on the echogenicity it gives the important information about the solid/cystic nature of the mass. Ultrasound is also the single most important radiological aid in calculating the risk of malignancy index (RMI) score based on the presence of ascites, nodules, unilaterality/bilaterality and presence of metastasis. For very large masses, the diagnosis needs to be complemented by CT to define the extent of the mass in its all dimensions as well as its relation with the surrounding structures and vessels, hence playing a vital role in planning the excision of mass.

The patients' age, size of the cyst and menopausal status of the patient are the important deciding factor in the plan of management. The commonly done procedures are exploratory laparotomy and excision of the mass, laparoscopic cyst excision/cystectomy with or without oophorectomy. Contralateral ovary should also be 
examined and frozen section should be planned if it looks suspicious. ${ }^{8}$ In the present case, gradual decompression of cyst was done followed by cystectomy. Similar approach was suggested by Hunter et al as it prevents rupture of the cyst capsule. ${ }^{9}$ Plan of approach i.e., laparotomy or laparoscopy must be case specific. A conservative surgical procedure should be the primary aim in order to preserve patient's fertility. ${ }^{10}$

\section{CONCLUSION}

Mucinous cystadenoma although rare, can present as a giant ovarian mass in adolescent girls. The size of the tumor and delayed detection can pose a challenge to the treatment. Case specific plan and complete excision are the cornerstone of the management.

Funding: No funding sources Conflict of interest: None declared

Ethical approval: Not required

\section{REFERENCES}

1. Sadeghian N, Sadeghian I, Mirshemirani A, Khaleghnejad Tabari A, Ghoroubi J, Abdollah Gorji $\mathrm{F}$ et al. Types and frequency of ovarian masses in children over a 10-year period. Caspian J Intern Med. 2015;6(4):220-3.

2. Brookfield KF, Cheung MC, Koniaris LG, Sola JE, Fischer AC. A population-based analysis of 1037 malignant ovarian tumors in the pediatric population. J Surg Res. 2009;156:45-9.

3. Brandt ML, Helmrath MA. Ovarian cysts in infants and children. Semin Pediatr Surg. 2005;14:78-85.

4. Schultz KA, Sencer SF, Messinger Y, Neglia JP, Steiner ME. Pediatric ovarian tumors: a review of 67 cases. Pediatr Blood Cancer. 2005;44(2):167-73.

5. Mortell A, Devaney D. Mucinous cystadenoma of the ovary in perimenarchal girls. Pediatr Surg Int. 2006;22:224.

6. Katke RD, Gohil D. Rupture and torsion of a huge ovarian cyst with ipsilateral para-ovarian cyst presented as haemoperitoneum and acute abdomen: A rare case report and review of literature. Int J Res Health Sci. 2014;2(4):1170-3.

7. Wootton-Gorges SL, Thomas KB, Harned RK, Wu SR, Wexler SR, Strain JD. Giant cystic abdominal masses in children. Pediatr Radiol. 2005;35(12):1277-88.

8. Nwobodo EI. Giant mucinous cystadenoma: case report. Niger J Clin Pract. 2010;13(2):228-9.

9. Hunter DJS. Management of a massive ovarian cyst. Obstet Gynecol. 1980;56:254-5.

10. Aggarwal A, Lucco KL, Lacy J, Kives S, Gerstle JT, Allen L. Ovarian epithelial tumors of low malignant potential: a case series of 5 adolescent patients. J Pediatr Surg. 2009;44(10):2023-7.

Cite this article as: Singh G, Narain A, Dhawan S, Kulshrestha R. Giant mucinous cystadenoma of ovary in an adolescent girl: a case report. Int J Reprod Contracept Obstet Gynecol 2021;10:404-6. 